\title{
Preliminary research of the thermomechanical properties of the round drive belts
}

\author{
Krzysztof Wałęsa*,1, Olga Mysiukiewicz ${ }^{2}$, Michat Pietrzak $^{1}$, Jan Górecki ${ }^{1}$, and Dominik \\ Wilczyński ${ }^{1}$ \\ ${ }^{1}$ Chair of Basics of Machine Design, Poznan University of Technology, Piotrowo 3 Street, 60-965 \\ Poznan, Poland \\ ${ }^{2}$ Polymer Division, Poznan University of Technology, Piotrowo 3 Street, 60-138 Poznan, Poland
}

\begin{abstract}
Most of the industrial machines use round-shaped drive belts for power transfer. These drive belts are often a few millimeters in diameter, and made of thermoplastic elastomer, especially polyurethane. Their production process requires the bonding step, which is often performed by hot plate butt welding. The authors have undertaken an effort to design an automatic welding machine, which calls for an analysis of the hot plate welding process consisting in describing the dependency between the technological parameters (temperature, pressure force, time) and the quality of the joint. To analyze this process in a proper way, it is necessary to describe the physical phenomena in the material during temperature and force impacts. In this case the research of thermomechanical properties of the belts is needed. The paper shows results of some preliminary research of the thermomechanical properties of the polyurethane. This research allows to predict the material reaction to increased temperature and force during hot plate welding.
\end{abstract}

Keywords: round belts, drive belts, polyurethane belts, compression test

\section{Introduction}

Drive belts are commonly used in industrial machinery as parts of the powertrain or transport system. Flat or toothed belts used for transportation are primarily made of composite materials: polyester, polyurethane or PVC, reinforced with fibers made of steel, aramid or polyester $[1,2]$. Apart from the classical flat belt design with filled cross-section, industrial practice also employs belts with perforations for low-pressure conveying system [3]. Among the most commonly utilized drive belt types are: flat, toothed and shaped (e.g. round and V-belts). Flat belts are most commonly used in high revolution speed powertrains. Toothed belts are used for in classic drive transmission systems as well as in non-standard applications, e.g. drive systems with variable ratio [4-7]. Shaped belts, in particular round and V-belts are commonly used in transmissions which are to transmit torque to significant distance and where belt slippage is permitted. Such belts may be made of rubber, rubber

\footnotetext{
* Corresponding author: krzysztof.walesa@put.poznan.pl

Reviewers: Maciej Bodnicki, Darina Ondrušowá
} 
composite as well as artificial thermoplastic elastomers based on polyurethane or polyester [8-10].

The manufacturing process of drive belts with round cross-section usually consists of two stages [11]: manufacturing the belt which is wound on rolls and afterwards cut to size, and making a permanent connection of the ends. This allows to achieve a continuous belt of specific length $[9,10]$.

Bonding the belt ends is usually achieved via hot plate butt welding. The method is inexpensive and easy to perform [12]. The authors have undertaken design work on a device for automatic butt welding of drive belts utilizing this method [10]. In order to obtain input data for construction works, examination of the welding process was undertaken. The aim of such examination was to determine the influence of process parameters on the quality of achieved weld as well as changes in the dimensions of bonded belt. In order to obtain such information, one must first of all determine the thermomechanical properties of the joined material.

It was assumed that the welding is to be performed on thermoplastic polyurethane TPU C85A [9]. Drive belts made of this plastic material are commonly available in commercial offerings. Unfortunately, the available information regarding the physical properties of this material in subject literature are very general [13]. Consequently, preliminary empirical study of selected thermomechanical properties of this plastic material was carried out, among others: density, longitudinal flexural modulus and compressive yield strength, thermal expansion coefficient and melting point together with the heat of this transformation.

\section{Material treatment in the hot plate welding process}

The hot plate butt welding process consists in five stages during which occur different physical phenomena (Fig. 1-5) [14, 15].

In the first stage of welding (Fig. 1), the belt ends (1) held in shaped grips (2) are brought closer to the hot plate (3) with velocity $v_{m}$, and afterwards pressed to the plate with force $F_{m}$. This causes preliminary softening of the material which removes the unevenness of the belt end surface. The most important physical phenomena occurring at this stage are: direct contact heat transfer between the hot plate and the belt, heat transfer along the diameter of the belt and its compression under the conditions of elevated temperature. Compression of plastic material heated up to temperature greater than the softening threshold, this causes the formation of a ring-shaped outflow thus shortening the belt.

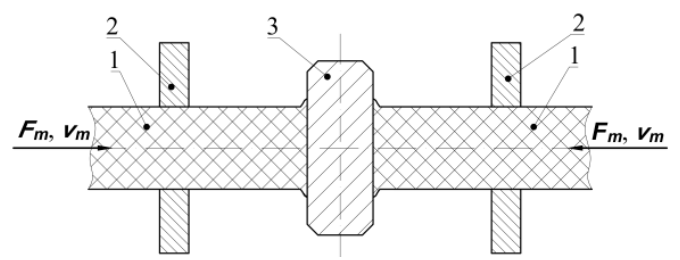

Fig. 1. The matching stage of the hot plate welding: $F_{m}$ - matching force, $v_{m}$ - matching velocity, 1 - belt, 2 - shaped grips, 3 - hot plate

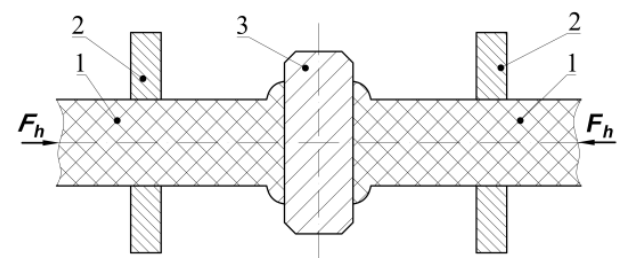

Fig. 2. The heating stage of the hot plate welding: $F_{h}$ - heating force, 1 - belt, 2 - shaped grips, 3 -hot plate 
During the second stage of the welding (Fig. 2), the heating of the belt is continued, however the joining force is reduced to the value $F_{h}$ (which is approximately $10-20 \%$ of the value of force $F_{m}$ ) [16]. Consequently, this prevents excessive outflow of softened material outside the area of the belt which allows for free transfer of heat into the material, along the belt's axis. This serves to reduce loss of material, prevents faulty joint formation [13] and increases heating efficiency [15]. The most prominent physical phenomena in this stage as the same as in stage one, but their intensity is different.

During the third stage (Fig. 3), after the belt achieves the required state of plasticity, the hot plate is withdrawn from the heating area. The physical phenomena occurring at this time are primarily: transmission of heat along the belt axis as a result of the occurring temperature gradient and free cooling of belt ends caused by natural convection.

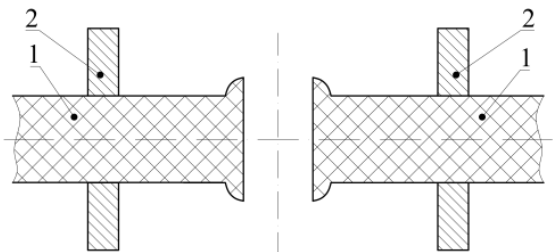

Fig. 3. The switchover stage of the hot plate welding: 1 - belt, 2 - shaped grips

During the joining stage (Fig. 4), the belt ends are brought close to each other with velocity $v_{j}$, and are pressed together with force $F_{j}$. At this stage, the following phenomena are dominant: heat transfer along the volume of the material, cooling of the surface as a result of natural convection, contact heat transmission between the ends of the belt and compression force which causes swelling of the material. During this stage, a permanent bond between the belt ends is formed as a result of physical and chemical interactions between the polymer chains. The primarily role in this process is fulfilled by the chemical reactions between macromolecules and the bonding of polymer chains [17].

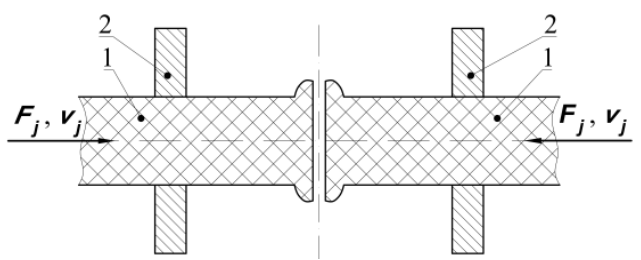

Fig. 4. The joining stage of the hot plate welding: $F_{j}$ - joining force, $v_{j}$ - joining velocity, 1 - belt, 2 - shaped grips

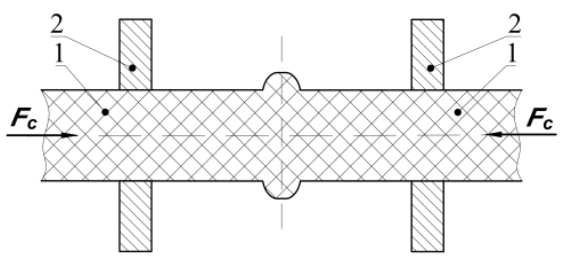

Fig. 5. The cooling stage of the hot plate welding: $F_{c}$ - compression force during cooling, 1 - belt, 2 - shaped grips

During the last stage of the welding (Fig. 5) the connection is cooled down by the surroundings. At that time, the belt ends are pressed together with force $F_{c}$. Its value is usually comparable to the belt matching force [16]. The dominant physical phenomena at this stage are: heat transfer along the belt material volume, heat exchange with the environment through 
natural convection and compressing forces. The polymer macromolecules continue to bond until the joint cools down completely.

Hot plate butt welding of polymer plastics is commonly utilized in the automotive industry and civil engineering to connect, e.g.: containers for utility fluids, lamp casings, engine instrumentation [17] and pipework [18]. Therefore, a body of research is available on hot-welding of different polymer materials, among others: acrylonitrile-butadiene-styrene (ABS) [19], poly(methyl methacrylate) (PMMA) [20], polycarbonate (PC) [21], as well as polypropylene (PP) [22]. Please note that to date the welding process for polymer materials of considerable rigidity was the most studied. It is therefore difficult to obtain information relevant to the joining of flexible plastics, such as thermoplastic elastomers, and polyurethane in particular.

During the hot-welding of drive belts, there occurs a number of physical phenomena of thermomechanical nature. The dominant phenomena are: heat conduction and material compression under conditions of elevated temperature. Therefore, for further study to account for the above physical phenomena, one needs to determine, among others: density, thermal expansion coefficient, specific heat, enthalpy and temperature of phase transitions, compressive strength and modulus of proportionality in compression, depending on temperature value.

\section{The basics of round drive belts' material characteristics}

Hot-welded polyurethane exhibits physical properties typical for thermoplastics and elastomers [23]. Its macrostructure is of segmented construction, with hydrocarbon chain consisting of alternating flexible domains: methylene, ester or ether, as well as rigid: carbamide, urethane or aromatic. Rigid domains are responsible for high durability parameters, whereas flexible domains significantly improve its deformability. The segments do not mix, forming a two-phase, heterogeneous structure [24-26]. The physical characteristics and properties are strongly dependent on the percentage share of rigid and flexible segments. A completely flexible polyurethane contains between $60-80 \%$ flexible segments. Most of the time, this results in high elasticity and deformability with quite good abrasion resistance $[25,27]$.

The segmented structure of polyurethane affects its physical state which is of particular importance during heating. The material is principally amorphous [28, 29]. However, one needs to point out that the rigid segments exhibit a tendency to form ordered structures similar to a crystalline arrangement. Therefore, under certain conditions, polyurethanes may be partially crystalline $[25,28]$. The rigid segments are interconnected with weak hydrogen bonds which slightly reticulate the material, this causes to exhibit properties related to elastomer plastics [24, 30, 31].

From the standpoint of analyzing the butt welding process of this material, it is important to determine its behavior under elevated temperature. Amorphous or slightly crystalline plastics such as polyurethane do not exhibit a prominent flow limit. Their state changes from vitreous, through thermoflexible leather-like, to thermoplastic and viscous [32]. When heated, reticulated materials may transform directly from vitreous state to highly flexible state, until thermal degradation occurs $[28,33]$. Therefore, it is anticipated that the tested polyurethane will exhibit the characteristic behaviors of both the amorphous and reticulated materials. As its temperature increases, the thermally unstable reticulating bonds disintegrate, which makes the material gradually more flexible [24, 33-35]. The dissolution and reforming of these bonds is reversible. This allows the material to be reprocessed. Moreover, notice that a clear threshold melting point value is not observable. From the practical standpoint, the properties of such thermoplastic elastomer are related to classic elastomer plastics up to the threshold temperature of approx. $100^{\circ} \mathrm{C}$. Above this temperature, the material acts like a typical thermoplastic material [29]. 


\section{Research methodology of selected thermomechanical properties of polyurethane}

The determination of thermodynamic properties of the plastic material calls for selecting the appropriate testing instrumentation. The examination was carried out using the available laboratory equipment: laboratory scale, durometer with climate box a DSC differential scanning calorimeter.

\subsection{The density examination}

Material density tests were carried out in the first order using AXIS AD200 laboratory scale with a stand equipped with two scale pans (Fig. 6).

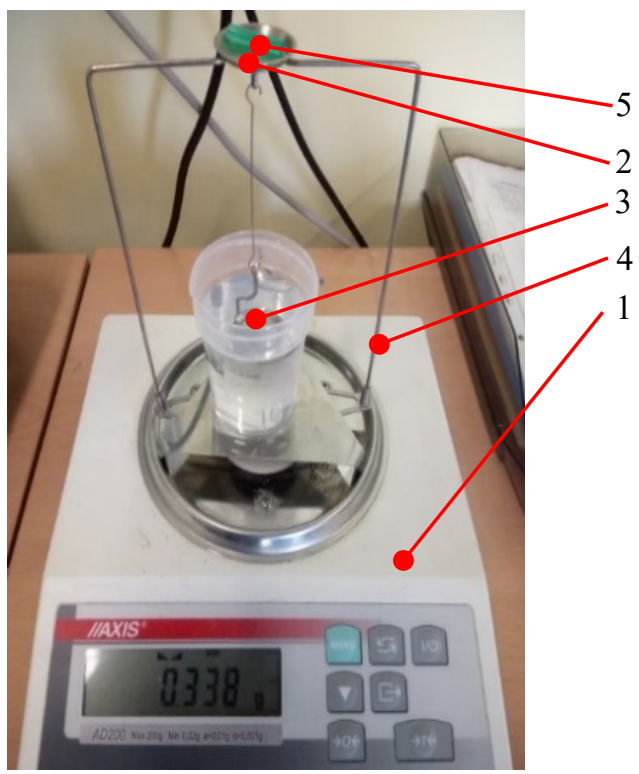

Fig. 6. Example density measurement of drive belt material, the sample on the scale pan is placed in the air: 1 - laboratory scale, 2 - scale pan in the air, 3 - scale pan in water, 4 -stand, 5 -sample

The cylindrical sample of tested belt $4 \mathrm{~mm}$ in diameter and approx. $10 \mathrm{~mm}$ in height, was weighted sequentially: on a scale pan in the air, and subsequently on a scale pan in water. Measuring both weights with known amount of water allows to determine material density using the below formula:

$$
\rho_{b}=\frac{m_{1}}{m_{2}} \cdot \rho_{w},
$$

where: $\rho_{b}$ - belt material density, $\rho_{w}$ - distilled water density, $m_{l}-$ weight of sample in air, $m_{2}$ - weight of sample in water.

The above method was utilized in 15 tests, under normal atmospheric conditions i.e.: atmospheric pressure approx. $1013 \mathrm{hPa}$ and room temperature $25^{\circ} \mathrm{C}$.

\subsection{Examination of compressive strength and flexural modulus during compression}

The compression test of drive belt material was carried out using MTS Insight 50 durometer with enclosed climate box (Fig. 7). 

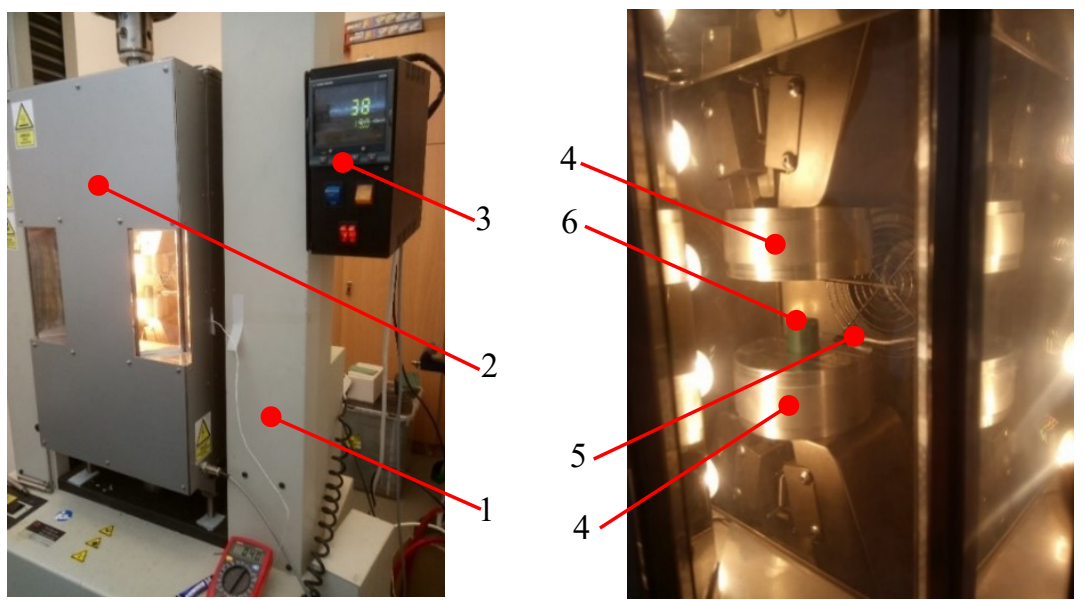

Fig. 7. Testing station for thermomechanical characteristics of drive belts with MTS Insight 50 durometer and climate box during examination: 1 - durometer, 2 - climate box, 3 - climate box controller, 4 - compressing grips, 5 - temperature sensor, 6 - sample before testing,

Compression tests were performed in order to establish: modulus of proportionality in compression and yield stress, at set level of strain as well as the dependence of these values on temperature. Consequently, the samples were conditioned in the climate box and the compression test was carried out afterwards. Tests were carried out for two parameter groups (Tab. 1), for which the values were selected based on the standards PN-EN ISO 604 and PN$80 / \mathrm{C}-04246$ on the compression of thermoplastic materials and elastomers. There were 5 tests carried out for all parameters. The relationship between stress and strain and modulus of proportionality were recorded in form of a graph.

Tab. 1. Thermomechanical testing parameters used with the durometer

\begin{tabular}{c|c|c}
\hline Examination & $\begin{array}{c}\text { Testing yield strength during } \\
\text { compression }\end{array}$ & $\begin{array}{c}\text { Determination of longitudinal } \\
\text { flexural modulus during } \\
\text { compression }\end{array}$ \\
\hline Sample type & \multicolumn{2}{|c}{$\begin{array}{c}\text { Cylindrical sample } \\
\text { diameter } d=18 \pm 0.2[\mathrm{~mm}] \\
\text { height } h=20 \pm 0.5[\mathrm{~mm}]\end{array}$} \\
& $\begin{array}{c}\text { The sample was cut off from an industrial grade belt with } \\
\text { diameter } 18 \mathrm{~mm} \text {, flat surfaces were processed by grinding, } \\
\text { diameter and height measured in } 3 \text { points }\end{array}$ \\
\hline Temperature conditions & $\begin{array}{c}\text { Testing temperatures: } 25 \pm 1,40 \pm 1,55 \pm 1,70 \pm 1, \\
85 \pm 1,100 \pm 2,125 \pm 2,150 \pm 2,175 \pm 2,200 \pm 2\left[{ }^{\circ} \mathrm{C}\right]\end{array}$ \\
\hline Initial load & \multicolumn{2}{|c}{$100 \pm 20[\mathrm{~N}]$} \\
\hline Crostening conditions & Grip with neck, sample end surface covered with silicone grease \\
\hline Test finish condition & $1 \mathrm{~mm} / \mathrm{min}$ & $10 \mathrm{~mm} /$ min \\
\hline & Relative strain & Relative strain \\
$\varepsilon=60 \%$
\end{tabular}

The grip used for compressing the samples is the authors' own design (Fig. 8). The cylindrical relief with diameter $25 \mathrm{~mm}$ and depth $1 \mathrm{~mm}$ used to place the samples prevented them from falling out of the grips during compression without inhibiting deformation of side surfaces. Sample end surfaces were covered with silicone grease suitable for temperatures up to $200^{\circ} \mathrm{C}$. This allowed to maintain axial stress of the sample during compression. 


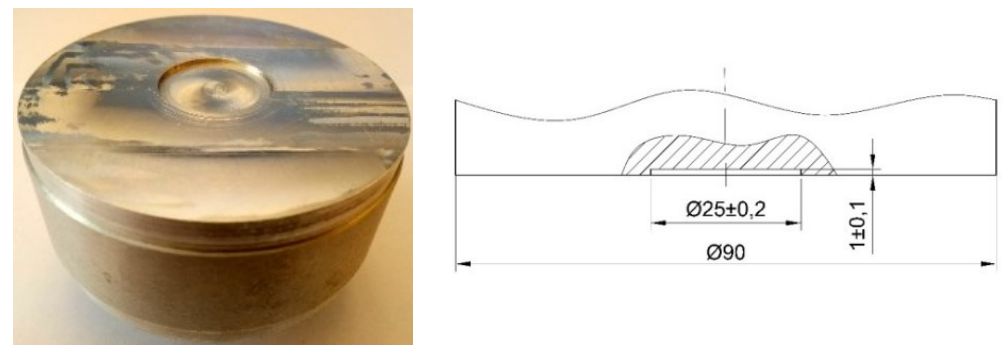

Fig. 8. The grip for sample compression of the authors' design with the most important parameters of the cylindrical relief

\subsection{Examination of thermal expansion coefficient}

In order to determine the linear thermal expansion value of the material, measurements were taken for the two characteristic dimensions of the belt sample heated to different temperatures in the climate box ( 2 at Fig. 7). The measurement of diameter and height of the samples was taken in 3 points (Fig. 9), and next the average value was calculated at different temperatures, every time for 10 samples.
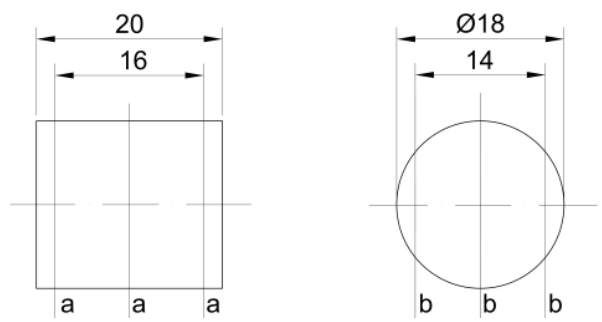

Fig. 9. Two views (according to the European technical drawing standard) of the compression and thermal expansion test sample; $a$ - diameter measurement planes, $b$ - height measurement planes

The linear thermal expansion coefficient, e.g. for sample height is calculated from the formula below (2):

$$
\alpha=\frac{h-h_{0}}{h_{0} \cdot \Delta T}\left[\frac{1}{K}\right]
$$

where: $h$ - sample height at test temperature $[\mathrm{mm}], h_{0}$ - sample height at temperature $T_{0}=25^{\circ} \mathrm{C}[\mathrm{mm}], \Delta T-$ the difference in temperature between the tested value and reference temperature $T_{0}=25^{\circ} \mathrm{C}$. The same calculations were performed for belt diameter.

The measurements were performed in temperatures: $25^{\circ} \mathrm{C}, 50^{\circ} \mathrm{C}, 75^{\circ} \mathrm{C}, 100^{\circ} \mathrm{C}, 125^{\circ} \mathrm{C}$, $150^{\circ} \mathrm{C}, 175^{\circ} \mathrm{C}$. The samples, both for the compression test and dimension measurement, were heated and conditioned in the climate box for approx. $1 \mathrm{~h}$ which allowed to achieve proper temperature at the entire sample volume. In order to determine the necessary conditioning time, a FEM analysis was performed in the ANSYS system. An example graph of average sample temperature during the process of heating up to $150^{\circ} \mathrm{C}$ together with a visualization of temperature distribution, after approx. 40 minutes, are shown at Fig. 10. In order to accurately reflect the conditions during heating in the climate box, for the purpose of FEM calculations, forced convection was assumed in the surrounding air with temperature $150^{\circ} \mathrm{C}$, with average heat transfer coefficient $15\left[\frac{\mathrm{W}}{\mathrm{m}^{2} \cdot \mathrm{K}}\right]$. Additionally, the initial temperature of $25^{\circ} \mathrm{C}$ was assumed together with the placement of the polyurethane sample on a steel plate. A finite element Cartesian grid was used with $1.1 \mathrm{~mm}$ scale, maintaining actual sample dimensions for the purpose of the analysis. 

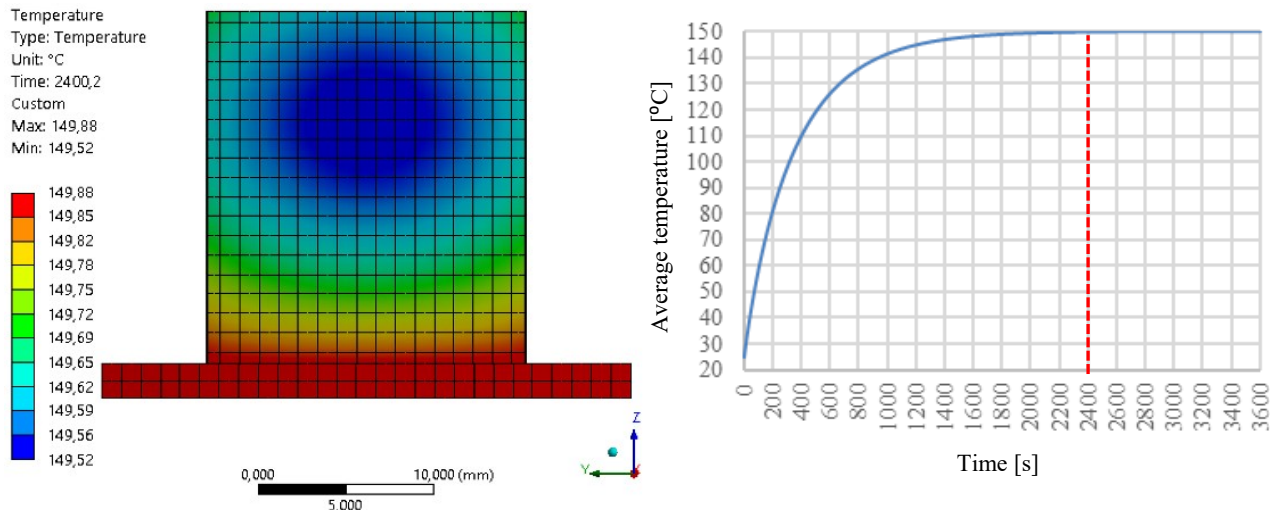

Fig. 10. Temperature distribution along the longitudinal cross section of the sample after 40 minutes, obtained via FEM analysis with an average temperature graph when heating up to $150^{\circ} \mathrm{C}$

Fig. 10 shows that the sample achieved an average temperature equal to $150 \pm 2{ }^{\circ} \mathrm{C}$ (one of the measuring points for compression and thermal expansion coefficient) after approx. 2400 seconds (40 minutes). The conditioning time was extended to 1 hour to assure an even distribution of temperature at the entire sample volume.

\subsection{Determination of phase transition temperature during heating}

In order to determine the phase transition, the material was heated using a differential scanning calorimeter DSC 204F1 Phoenix. This device allows, among others, to determine the heat supplied to the sample as a function of its temperature. This allows to estimate the phase transition temperature as well as their enthalpy. The weighted material sample was heated at constant speed, and subsequently cooled down in the same manner; at the same time, the power supplied to or emitted by the sample was measured as a function of its temperature. The test parameters are provided in Tab. 2 below.

Tab. 2. Parameters of testing performed at the DSC scanning calorimeter

\begin{tabular}{c|c|c}
\hline Test & Heating & Cooling \\
\hline Sample type & \multicolumn{2}{|c}{ Sample taken from a flat belt with thickness $g=4[\mathrm{~mm}]$} \\
\hline $\begin{array}{c}\text { Temperature } \\
\text { conditions }\end{array}$ & \multicolumn{2}{|c}{ Sample weight $m=10.3[\mathrm{mg}]$} \\
\hline Atmosphere & with speed $10\left[{ }^{\circ} \mathrm{C} / \mathrm{min}\right]$ & Cooling down from 320 to $20\left[{ }^{\circ} \mathrm{C}\right]$ \\
\hline \multicolumn{2}{|c}{ Nitrogen $\mathrm{N}_{2}$ with expenditure $20[\mathrm{ml} / \mathrm{min}]$} \\
\hline
\end{tabular}

During the heating and cooling in the differential scanning calorimeter, if no phase transition is present, the curve of power supplied for heating the sample (or emitted during the cooling) is a straight line (with inclination dependent on specific heat). In the course of phase transition: melting (endothermal) it is required to provide heat to the material at constant temperature, whereas for solidification (exothermal), the same amount of heat needs to be emitted. On the graph illustrating the dependence of supplied power for heating the sample (or emitted during cooling), the phase transitions are revealed through aberrations (peaks) of power. This allows to read the temperature of the transition as well as its enthalpy which is determined by the area under the curve [36].

\section{Results and discussion}

The obtained results of study will be used for further research work on the hot plate welding process of this material. 


\subsection{Density examination}

The arithmetic mean from the calculated density values according to the function (1) is $1.168 \mathrm{~g} / \mathrm{cm}^{3}$. Every attempt to determine the density of the material produced a relatively similar result. The maximum relative error of measurement was $1.85 \%$.

\subsection{Examination of compression strength and flexural modulus at compression}

An example diagram of belt compression presenting the stress - strain function, for both attempts (compression at speed $1 \mathrm{~mm} / \mathrm{min}$ to $30 \%$ strain and with speed $10 \mathrm{~mm} / \mathrm{min}$ to yield strain $60 \%$ ) is shown on Fig. 11. As seen, repeatable results were achieved. The material exhibits a non-linear characteristic with two points of contra flexure (at strain approx. 6\% and $50 \%$ ). In the range of strain not exceeding $5 \%$, in both cases the strain function is a straight line, thus allowing to determine the modulus of proportionality at compression. The presented characteristics also reveal that the modulus of proportionality at compression does not depend on the speed of performing the examination. Only during the compression of this material to higher strain values, rigidity increases together with the increase of speed.

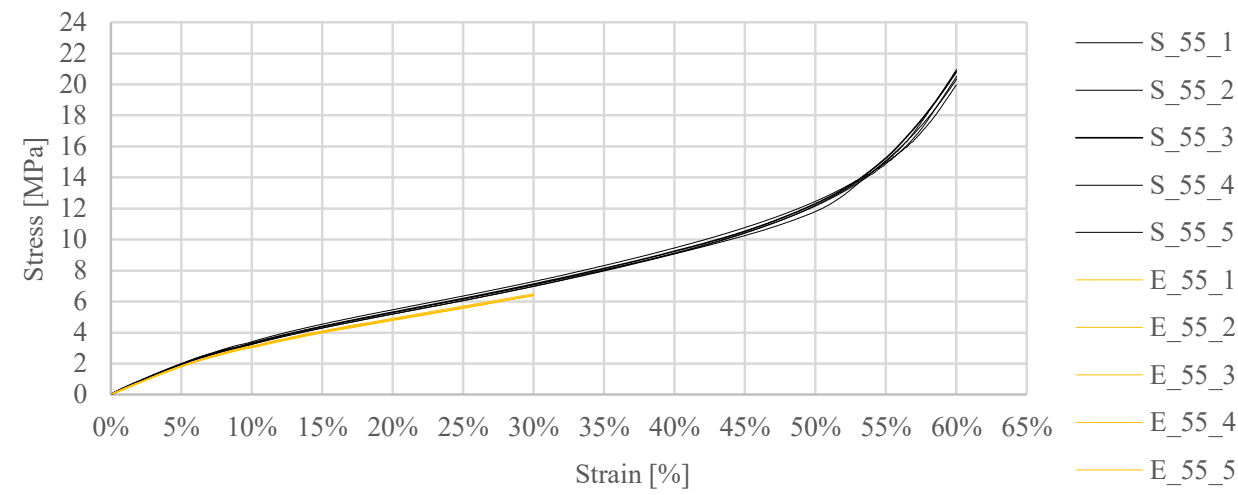

Fig. 11. Example graph of compression graph function (stress - strain) for: compression speed $1 \mathrm{~mm} / \mathrm{min}$, yield strain $30 \%$ (E_55_1...5, yellow line) and for compression speed $10 \mathrm{~mm} / \mathrm{min}$, yield strain $60 \%$ (S_55_1...5, black line), temperature during test $55^{\circ} \mathrm{C}$

Based on the obtained results, the function of the flexural modulus and temperature at compression was determined (Fig. 12) together with the function of yield stress and temperature at maximum strain for both types of examinations (Fig. 13).

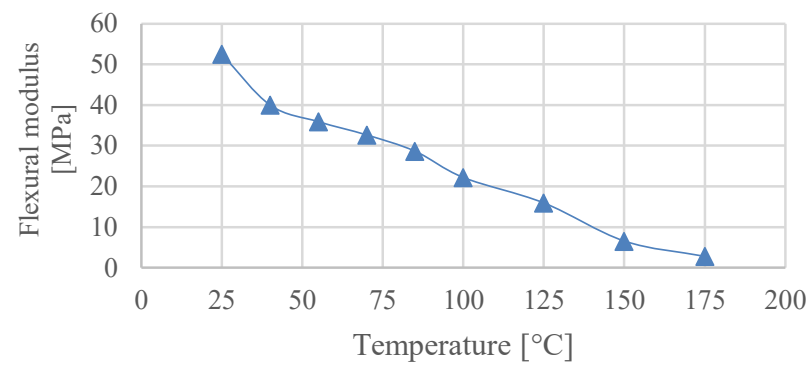

Fig. 12. The function of longitudinal flexural modulus and sample temperature during compression

The function is decreasing in linear way. This stems from the fact that with the increase of temperature, the reticulating bonds between macromolecule chains break which causes a decrease in rigidity and strength of the material. For this polymer which is amorphous, 
slightly reticulated, this decrease is linear. This is caused by the fact that it does not exhibit clear physical changes as the temperature increases to $175^{\circ} \mathrm{C}$. Above this temperature, the samples were not tested because they deformed autogenously, without action by compressing forces. Additionally, in temperature value $175^{\circ} \mathrm{C}$, the sample material failure occurred at yield stress not exceeding $1 \mathrm{MPa}$ and strain of approx. 35\%. In lower temperatures, clear failure of sample material was not observed.

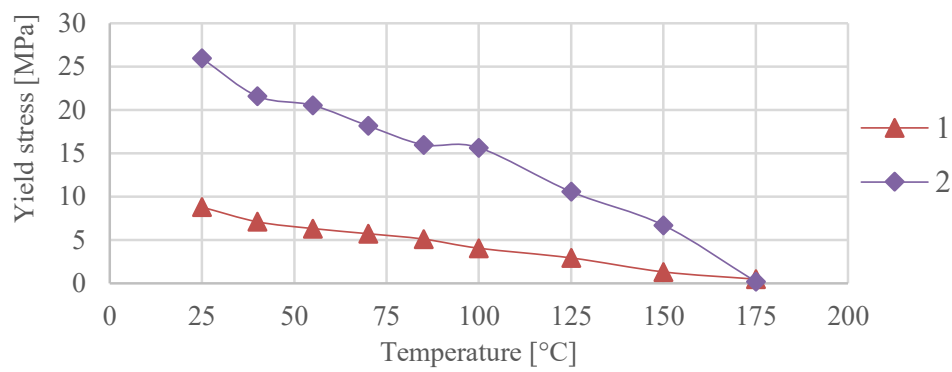

Fig. 13. The function of yield stress during belt compression: for yield strain $30 \%$ and compression speed $1 \mathrm{~mm} / \mathrm{min}$ (1) and yield strain $60 \%$ at compression speed $10 \mathrm{~mm} / \mathrm{min}$ (2)

\subsection{Examination of the material thermal expansion coefficient}

The coefficient of linear thermal expansion as a function of temperature was determined, separately for the sample diameter and length, following the function (2) (Fig. 14). The thermal expansion coefficient, both for the diameter and length decreases together with the increase of belt temperature up to $125^{\circ} \mathrm{C}$, afterwards it stays on the same level. The irregularity of this decrease is caused by the variable speed of dissolution of the reticulating chemical bonds between polymer chains. This leads to a conclusion that up to temperature value of approx. $125^{\circ} \mathrm{C}$ an increased dissolution of reticulating bonds occurs causing decompression of the polymer structure. For this reason, in lower temperatures the sample increases its dimensions noticeably faster in lower temperatures. The dependency between the established coefficient is also relevant. Radial expansion (for sample diameter) is noticeably greater than in the axial dimension (lengthwise), this may indicate that the plastic is not entirely isotropic. This issue indubitably calls for further study.

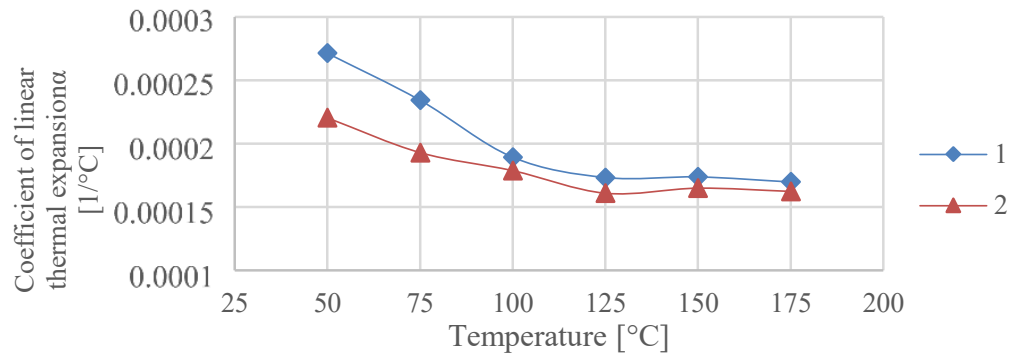

Fig. 14. The function of the thermal expansion coefficient and temperature for: sample diameter (1) and sample length (2)

\subsection{Determination of temperature of phase transition during heating}

The examination of the phase transition point of the studied material together with identifying the enthalpy of this transition allowed to determine the function graph for the power required to heat the sample and emitted during cooling, depending on its temperature value (Fig. 15). As seen on the presented graph, during heating (A), the power supplied to the sample within 
the temperature range of approx. $30^{\circ} \mathrm{C}$ to approx. $300^{\circ} \mathrm{C}$ is constant. There were no observed irregularities in form of peaks - which would indicate a phase transition. Similarly for cooling (B), the power increases linearly. What follows, it is not possible to determine an exact melting point. Consequently, it is not possible to determine the enthalpy for this transformation.

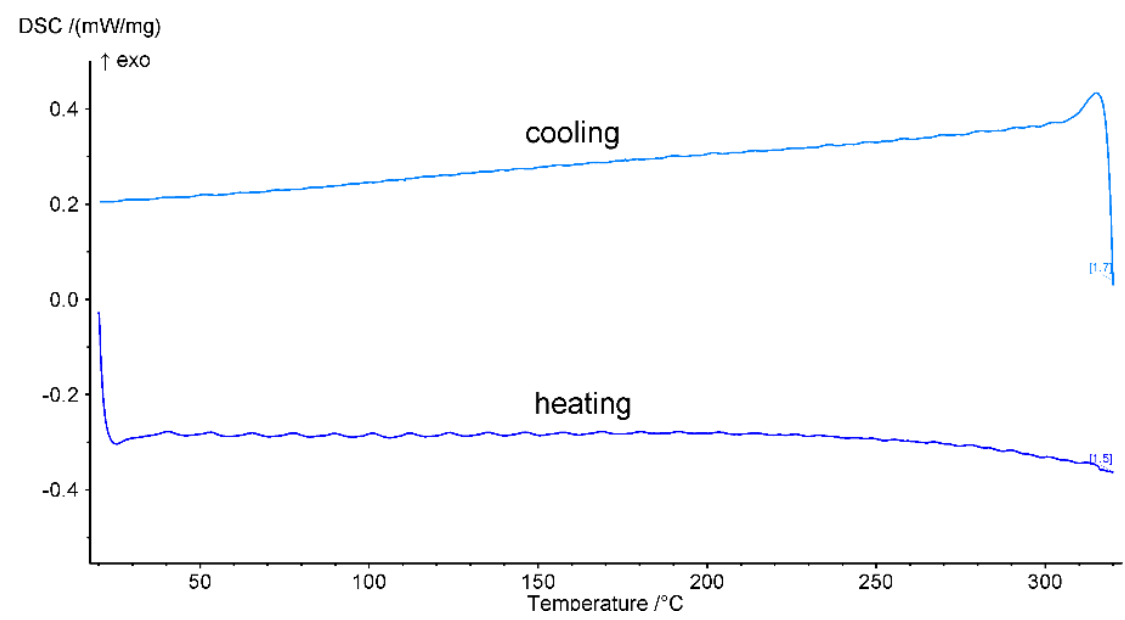

Fig. 15. Example graph line for heating (A) and cooling (B) of the test sample employing the differential calorimeter method - DSC

\section{Conclusions}

The results of preliminary examination of the thermomechanical properties of the material used to manufacture drive belts demonstrate that its characteristics are strongly dependent on temperature.

Material density examination results indicate that it is relatively low in comparison to other polymer plastics used in construction, e.g. polyamide, polyacetal and rubber.

Compression tests of the studied material samples brought about predictable results. The stress - strain functions are not linear which is typical for plastics. In the range of insignificant strains $(\varepsilon<5 \%)$, regardless of strain velocity, the compression graphs are linear (proportional range), this allows to determine the modulus of proportionality. Both the yield stress at compression, with strain of $30 \%$ and $60 \%$ as well as the flexural modulus decrease linearly as a function of temperature. Such behavior is highly predictable. The boundary temperature at which the samples maintain mechanical compression strength is approximately $150^{\circ} \mathrm{C}$. This examination is highly important from the standpoint of butt welding analysis because the dominant state of this process is compression in elevated temperature.

The examination of thermal expansion of the plastic material brought about unexpected results. The change of the thermal expansion coefficient value $\alpha$ as a function of temperature necessitates a further study of the material heating transitions at the level of molecular structure. An interesting factor is the difference between the thermal expansion coefficient for sample diameter (radial direction) and sample height (axial direction). This means that the properties of the material as not entirely isotropic. This fact will be taken into consideration during formulation of the mathematical model for this material.

An attempt to determine the temperature of phase transition of the examined polyurethane material failed to bring about the expected result. The results obtained via differential scanning calorimetry do not allow to determine the melting point for this material and even more so the enthalpy of this transition. This is a consequence of the fact that the plastic material is most likely amorphous and reticulated, and therefore such parameters are 
impossible to determine. In order to make sure that the obtained results are not solely caused by a wrong selection of testing method (DSC) one needs to attempt to determine the phase transition temperature via a different method, e.g. by determining the flow rate curve using a rotational rheometer [36]. Additionally, it is necessary to examine the degree of crystallinity of this plastic material, e.g. via determining the spectrum obtained after infrared or X-ray scanning (the WASX, SAXS methods) [37].

The results of the carried out examinations will be extremely helpful in the further analysis of the butt welding process of this material due to the exact mapping of the physical properties occurring during the hot plate welding process.

\section{References}

1. D. Wojtkowiak, K. Talaśka, I. Malujda, G. Domek, Analysis of the influence of the cutting edge geometry on parameters of the perforation process for conveyor and transmission belts. MATEC Web of Conferences 157: 01022 (2018)

2. K. Talaśka, D. Wojtkowiak, Modelling a mechanical properties of the multilayer composite materials with the polyamide core. MATEC Web of Conferences 157: 02052 (2018)

3. D. Wojtkowiak, K. Talaśka, I. Malujda, G. Domek, Estimation of the perforation force for polymer composite conveyor belts taking into consideration the shape of the piercing punch. The International Journal of Advanced Manufacturing Technology (2018) https://doi.org/10.1007/s00170-018-2381-3

4. P. Krawiec, Analysis of selected dynamic features of a two-wheeled transmission system. Journal of Theoretical and Applied Mechanics 55 (2), 461-467 (2017)

5. M. Kujawski, P. Krawiec, Analysis of generation capabilities of noncircular cogbelt pulleys on the example of a gear with an elliptical pitch line. Journal of Manufacturing Science and Engineering - Transactions of the Asme 133 (5), 61-67 (2011)

6. G. Domek, M. Dudziak, Energy Dissipation in Timing Belts Made From Composite Materials. Advanced Material Research 189, 4414-4418 (2011)

7. G. Domek, I. Malujda, Modeling of timing belt construction, Proceedings in Applied Mathematics and Mechanics 7, 45-46 (2007)

8. M Kukla, J. Górecki, I. Malujda, K. Talaśka, P. Tarkowski, The determination of mechanical properties of magnetorheological elastomers (MREs). Procedia Engineering 177, 324-330 (2017)

9. Behabelt, Product Catalogue 2015/2016, Behabelt, Glotteral, (2015)

10. K. Wałęsa, I. Malujda, K. Talaśka, Butt welding of round drive belts. Acta Mechanica et Automatica 12 (2), 115-126 (2018)

11. R. Sikora, Przetwórstwo tworzyw wielkocząsteczkowych, Wydawnictwo Żak, Warszawa (1993)

12. N. Amanat, N. L. James, D.R. McKenzie, Welding methods for joining thermoplastic polymers for the hermetic enclosure of medical devices. Medical Engineering \& Physics 32, 690-699 (2010)

13. K. Wałęsa, I. Malujda, K. Talaśka, Experimental research of round welded drive belts. Mechanik 5-6, 443-446 (2018)

14. H. Potente, J. Schneiders, M. Bornemann, Theoretical model for the one-dimensional temperature and stress calculation of simple hot plate welded geometries. Macromolecular Materials and Engineering 287, 843-853 (2002)

15. K. Wałęsa, I. Malujda, K. Talaśka, M. Pietrzak, D. Wilczyński, Process analysis of hot plate welding of drive belts. Machine dynamics research, (2018, in press)

16. A. Klimpel, Spawanie i zgrzewanie tworzyw termoplastycznych. Wydawnictwo Politechniki Śląskiej, Gliwice (2000) 
17. D. Grewell, A. Benatar, Welding of Plastics: Fundamentals and New Developments. International Polymer Processing 22 (1), 43 - 60 (2007)

18. M. Troughton (eds.), Handbook of Plastics Joining: A practical guide. Plastics Design Library, New York (1997)

19. A. Mokhtarzadeh, A. Benatar, Experiments with conventional and high temperature hot plate welding of thermoplastics using temperature and pressure control. ANTEC 2012 Plastics: Annual Technical Conference Proceedings, 1684-1690 (2012)

20. A. Mokhtarzadeh, $\mathrm{Ch}$. Wu, A. Benatar, Comparison of hot plate and vibration welding of PMMA to ABS. ANTEC 2008 Plastics: Annual Technical Conference Proceedings, $856-861(2008)$

21. C. Krishnan, A. Benatar, Analysis of Residual Stress in Hot Plate Welded Polycarbonate. ANTEC 2004 Plastics: Annual Technical Conference: Processing (1), 1149 - 1153 (2004)

22. J. Nieh, J. Lee, Hot Plate Welding of Polypropylene Part I: Crystallization Kinetics. Polymer Engineering and Science 38 (7), 1121 - 1132 (1998)

23. M. F. Ashby, D. R. H. Jones, Materiały inżynierskie. WNT, Warszawa (1996)

24. D. Żuchowska, Polimery konstrukcyjne. WNT, Warszawa (2000)

25. A. Puszka, Poliuretany - surowce, właściwości oraz modyfikacje. Lublin (2004)

26. L. A. Ting, L. Cheing-Wen, L. Jia-Horng, The Effects of Thermoplastic Polyurethane on the Structure and Mechanical Properties of Modified Polypropylene Blends. Applied Sciences (2017) https://doi.org/10.3390/app7121254

27. E. G. Bajsić, A. Pustak, I. Śmit, M. Leskovac, Blends of Thermoplastic Polyurethane and Polypropylene. II. Thermal and Morphological Behavior. Journal of Applied Polymer Science 117 (3), 1378-1384 (2010)

28. K. Kelar, D. Ciesielska, Fizykochemia polimerów: wybrane zagadnienia. Wydawnistwo Politechniki Poznańskiej, Poznań (1997)

29. A. Ciszewski, T. Radomski, Materiaty konstrukcyjne $w$ budowie maszyn. PWN, Warszawa (1989)

30. L. Wanqing, F. Changqing, Z. Xing, C. Youliang, Y. Rong, L. Donghong, Morphology and thermal properties of polyurethane elastomer based on representative structural chain extenders. Thermochimica Acta 653, 116-125 (2017)

31. L. Wanqing, F. Changqing, Z. Xing, L. Jiabin, C. Youliang, Y. Rong, Z. Zisen, L. Donghong, Thermal properties of polyurethane elastomer with different flexible molcular chain based on para-phenylene diisocyanate. Journal of Materials Science \& Technology 33, 1424-1432 (2017)

32. L. Dobrzański, Podstawy nauki o materiałach. WNT, Gliwice (2002)

33. A. Błędzki, Laboratorium z fizykochemii polimerów. Wydawnictwo Politechniki Szczecińskiej, Szczecin (1980)

34. E. Yildirim, M. Yurtsever, G. L. Wilkes, I. Yilgor, Efect of intersegmental interactions on the morphology of segmented polyuretahnes with mixed soft segments : A coarsegrained simulation study. Polymer 90, 204-214 (2016)

35. M. Shoaib, A. Bahadur, S. Iqbal, M. S. U. Rahman, S. Ahmed, G. Shabir, M. A. Javaid, Relationship of hard segment concentration in polyurethane-urea elastomers with mechanical, thermal and drug release properties. Jounrnal od Drug Delivery Science and Technology 37, 88-96 (2017)

36. W. Przygocki, Metody fizyczne badań polimerów. PWN, Warszawa (1990)

37. T. Rydzkowski, Badanie struktury polimerów. Stopień krystaliczności. Teka Komisji Budowy i Eksploatacji Maszyn, Elektroniki i Budownictwa PAN, 143-148 (2008) 